\title{
Deriva Simulada do Glyphosate em Cultivares de Café Acaiá e Catuca $\hat{\mathbf{I}}^{1}$
}

\author{
Simulated Glyphosate Drift on Acaiá and Catucaí Coffee Cultivars \\ FRANÇA, A.C. ${ }^{2}$, CARVALHO, F.P..$^{3}$, FIALHO, C.M.T. ${ }^{3}$, D’ANTONINO, L. ${ }^{4}$, SILVA, A.A. ${ }^{5}$, \\ SANTOS, J.B. ${ }^{2}$ e FERREIRA, L.R. ${ }^{5}$
}

\begin{abstract}
RESUMO - O objetivo desta pesquisa foi avaliar os efeitos da deriva simulada de glyphosate sobre o crescimento inicial de dois cultivares de café de crescimento distinto. Utilizou-se o delineamento em blocos casualizados com quatro repetições, sendo os tratamentos distribuidos em esquema fatorial $2 \times 5$. No primeiro fator foram alocados os cultivares e, no segundo, as subdoses do glyphosate $(0,57,6 ; 115,2 ; 230,4 ;$ e 460,8 g ha-1). No dia da aplicação e também aos 45 e 120 dias após aplicação (DAA), avaliaram-se a altura, a área foliar, o diâmetro do caule, o número de ramos plagiotrópicos e de folhas; aos 10, 45 e 120 DAA foram avaliados os sintomas de intoxicação nas plantas e, aos 120 DAA, o acúmulo de massa seca de caule, folhas e raizes. Os sintomas de intoxicação nas plantas de café causados pelo glyphosate foram caracterizados por clorose e estreitamento do limbo foliar nos dois cultivares estudados. Todavia, sintomas mais severos foram verificados no cultivar Acaiá a partir de 10 DAA, como necrose de folhas mais novas da parte mediana da planta. Conclui-se que o cultivar Acaiá é menos tolerante ao glyphosate, quando comparado ao Catucaí, pois apresentou menor crescimento que o Catucaí quando submetidos ao tratamento com o herbicida, ou seja, pode ocorrer tolerância diferencial entre cultivares de crescimento distinto.
\end{abstract}

Palavras-chave: Coffea arabica, herbicida, EPSPs.

\begin{abstract}
This study aimed to evaluate the effects of simulated glyphosate drift on the growth of two cultivars with distinct growing patterns. The experiment was arranged in a randomized block design, with four repetitions, and the treatments were distributed in a factorial scheme $2 x 5$, with two cultivars in the first factor and the glyphosate subdoses $\left(0,57.6 ; 115.2 ; 230.4\right.$ and $\left.460.8 \mathrm{~g} \mathrm{ha}^{-1}\right)$ in the second factor. On the day glyphosate was applied and at 45 and 120 days after application (DAA), height, leaf area, stem diameter, and number of plagiotropic branches and leaves were evaluated; at 10, 45 and $120 \mathrm{DAA}$, plant intoxication symptoms were visually evaluated and at 120 DAA, dry mass accumulation of the stem, leaves, and roots was evaluated. The intoxication symptoms of the coffee plants caused by glyphosate were characterized by chlorosis and leaf narrowing in the two cultivars studied. However, more severe symptoms were verified in the Acaia cultivars from 10 DAA on, such as necrosis of younger leaves in the median part of the plant. It was concluded that Acaiá cultivar is less tolerant to glyphosate than Catucai cultivar, since it showed lower growth when submitted to herbicide treatment, i.e., tolerance can vary between cultivars with distinct growing patterns.
\end{abstract}

Keywords: Coffea arabica, herbicide, EPSPs.

1 Recebido para publicação em 15.8.2012 e aprovado em 14.11.2012.

2 Professor Adjunto, Faculdade de Ciências Agrárias, Universidade Federal dos Vales do Jequitinhonha e Mucuri - FCA/UFVJM, Campus JK, Rodovia MGT 367, Km 583, no 5000 Bairro Alto do Jacuba, 39100-000 Diamantina-MG, <cabralfranca@yahoo.com.br>, <jbarbosasantos@yahoo.com.br>; ${ }^{3}$ Doutorando do Dep. de Fitotecnia, Universidade Federal de Viçosa - DFT/UFV, 36570-000 Viçosa-MG, <felipepaolinelli@yahoo.com.br>, < cintiamtfialho@yahoo.com.br>; ${ }^{4}$ Engo-Agrōe., D.Sc., DFT/UFV, <leonardo@ufv.br>; ${ }^{5}$ Professor Associado, DFT/UFV, <aasilva@ufv.br>, <lroberto@ufv.br>

Planta Daninha, Viçosa-MG, v. 31, n. 2, p. 443-451, 2013 


\section{INTRODUÇÃO}

O Brasil lidera há dois séculos a produção mundial de café, e sua história política, econômica e social sempre esteve vinculada à cultura. A produção brasileira na safra de 2011/2012 foi estimada em 50,48 milhões de sacas de café. Entre os Estados produtores de café, particularmente de Coffea arabica, Minas Gerais destaca-se como o maior, com produção prevista em torno de 26,63 milhões de sacas, o que corresponde aproximadamente a $53 \%$ da produção nacional (Conab, 2012).

No entanto, apesar da grande produção nacional, a cafeicultura brasileira apresenta baixa produtividade, com média nacional de 24,55 sacas ha-1 ${ }^{-1}$ registrada na safra de 2011/ 2012 (Conab, 2012). Essa baixa produtividade deve-se, em parte, a lavouras antigas e depauperadas, deficiências nutricionais, baixa tecnologia de produção e problemas no manejo da cultura.

Entre os principais problemas encontrados pelos cafeicultores, destaca-se o manejo das plantas daninhas, devido ao efeito adverso na produção e no crescimento do cafeeiro através da competição imposta por essas plantas pelos recursos disponiveis (Ronchi et al., 2003).

Para Silva et al. (2008), o primeiro ano após o plantio das mudas no campo é caracterizado como a fase mais critica de controle das plantas daninhas na cultura. Plantas de cafeeiro, ainda jovens, deixam grande área de solo exposta à luz, favorecendo o crescimento das espécies daninhas. Além disso, cafeeiros jovens apresentam crescimento mais lento, quando comparado ao das plantas daninhas, favorecendo a competição. Nesse sentido, em razão do reduzido número de herbicidas registrados e que apresentam seletividade à cultura do café, o controle de plantas daninhas torna-se um processo oneroso.

Muitos cafeicultores utilizam herbicidas não seletivos, como o glyphosate, empregados em aplicações dirigidas, a fim de tornar o processo mais econômico. Para a eficiência da aplicação desse herbicida, há necessidade de equipamentos e técnicas apropriadas que evitem o contato das gotas pulverizadas com as plantas de café. Utilizam-se, para esse fim, barreiras físicas, pontas com indução de ar, adição de óleo vegetal à calda de pulverização, além de cuidados com a pressão de trabalho, altura da barra, velocidade de operação e do vento. Contudo, apesar de todos os cuidados com a tecnologia de aplicação, são constatados casos de intoxicação em lavouras de cafeeiro devido à deriva acidental do produto.

Wolf et al. (1992) demonstraram que o movimento de herbicidas para as plantas não alvo durante uma aplicação pode variar de 1 a $10 \%$ do equivalente aplicado. Em diferentes culturas perenes têm-se observado efeitos prejudiciais da deriva de glyphosate nas plantas, a exemplo do cafeeiro (França et al., 2010a,b), eucalipto (Tuffi Santos et al., 2007, 2009) e citros (Gravena et al., 2009). Contudo, existe carência na literatura de pesquisas que elucidam os efeitos da deriva do glyphosate sobre o crescimento de cultivares de cafeeiro e, particularmente, sobre cultivares de crescimento distinto.

Alguns cafeicultores relatam de forma empírica que cultivares de porte alto são mais sensiveis a efeitos provocados por substâncias tóxicas, como fitotoxicidade de fungicidas, inseticidas e herbicidas, e por condições climáticas adversas, como geadas e ventos fortes. Assim, partindo do pressuposto da sensibilidade diferenciada em função do hábito de crescimento do cafeeiro, objetivou-se, neste trabalho, avaliar os efeitos da deriva de glyphosate sobre o crescimento inicial de dois cultivares de cafeeiro de crescimento distinto.

\section{MATERIAL E MÉTODOS}

As mudas de cafeeiro dos cultivares Acaiá (IAC 474/19) e Catucaí Amarelo (2 SL) foram produzidas por semeadura direta, utilizandose como recipientes sacos próprios para mudas de cafeeiro de polietileno com capacidade de $500 \mathrm{~mL}$, preenchidos com substrato, constituído de amostra de solo de subsolo peneirado e esterco de curral curtido (3:1 v/v), e adubados com $5 \mathrm{~g} \mathrm{dm}^{-3}$ de superfosfato simples e $1 \mathrm{~g} \mathrm{dm}^{-3}$ de cloreto de potássio por decímetro cúbico de substrato. As mudas foram mantidas em casa de vegetação telada e sob irrigação por aspersão diária.

No estádio de cinco pares de folhas completamente expandidas, as mudas foram transplantadas para vasos de polietileno com 
capacidade de $15 \mathrm{~L}$ e mantidas em casa de vegetação. Os vasos, contendo uma planta cada, constituíram as parcelas experimentais e foram preenchidos com substrato composto por solo peneirado de textura argiloarenosa (49\% de argila, $5 \%$ de silte e $46 \%$ de areia) e esterco de curral curtido, respectivamente, na proporção de 3:1 (v/v). A análise química do solo apresentou o seguinte resultado: $\mathrm{pH}$ (água) de 4,7; teor de matéria orgânica de 2,4 daq $\mathrm{kg}^{-1}$; $\mathrm{P}$ e K de 2,3 e $48 \mathrm{mg} \mathrm{dm}^{-3}$, respectivamente; e $\mathrm{Ca}, \mathrm{Mg}, \mathrm{Al}, \mathrm{H}+\mathrm{Al}$ e $\mathrm{CTC}_{\text {efetiva }}$ de 1,4, 0,4, 0,6, 6,3 e $2,52 \mathrm{cmol}_{\mathrm{c}} \mathrm{dm}^{-3}$, respectivamente.

Para elevar a saturação por bases a $60 \%$, utilizou-se $1,1 \mathrm{~kg} \mathrm{ha}^{-1}$ de calcário dolomítico (PRNT 90\%). Após período de incubação do solo para reação do calcário, aplicou-se superfosfato simples (150 g por vaso) e, aos 30 e 60 dias após o transplantio, parcelou-se cloreto de potássio $(51,72 \mathrm{~g}$ por vaso) e ureia $(11,36 \mathrm{~g}$ por vaso). Toda a adubação foi baseada na análise de solo e nas recomendações de Guimarães et al. (1999).

As parcelas (vasos) foram dispostas em delineamento de blocos casualizados, sendo os tratamentos constituídos pelo esquema fatorial $2 \times 5$, com quatro repetições. $O$ primeiro fator foi constituído pelos cultivares Acaiá (IAC 474/19) e Catucaí Amarelo (2 SL), e o segundo, pelas doses de glyphosate, que foram de: $0 ; 57,6 ; 115,2 ; 230,4$ e 460,8 $\mathrm{g} \mathrm{ha}^{-1}$ de glyphosate, correspondentes a $0,4,8,16$ e $32 \%$ da dose comercialmente recomendada (1.440 $\left.\mathrm{g} \mathrm{ha}^{-1}\right)$, respectivamente.

Aos 120 dias após o transplante, quando as plantas apresentavam altura média de 44 e $52 \mathrm{~cm}$, para Catucaí e Acaiá, respectivamente, a aplicação foi realizada passando-se a barra de pulverização rente ao topo das plantas, de modo a não atingir o terço superior das plantas. Foi utilizado um pulverizador costal, pressurizado a $\mathrm{CO}_{2}$, munido com barra com duas pontas de pulverização tipo leque (TT 11002), espaçadas de $50 \mathrm{~cm}$ entre si, calibrado na pressão constante de $250 \mathrm{kPa}$, que proporcionou $200 \mathrm{~L} \mathrm{ha}^{-1}$ de volume de calda.

Paralelamente, avaliou-se a quantidade recebida do produto por secções da planta. Para isso, utilizou-se calda de pulverização contendo somente corante hidrossolúvel vermelho Xadrez, na concentração de $5 \mathrm{~mL} \mathrm{~L}^{-1}$. Em seguida, distribuíram-se etiquetas de papel cartão padrão $(2,5 \times 7,5 \mathrm{~cm})$, fixando-as em todas as folhas completamente desenvolvidas de quatro plantas dos dois cultivares trabalhados, destinados especificamente para esse teste. A aplicação foi feita passando-se a barra de pulverização rente ao topo das plantas. Após aplicação, as etiquetas foram imediatamente digitalizadas por câmera fotográfica com resolução de $6.0 \mathrm{Mpixels}$, para posterior análise no programa computacional Image Tool $^{\circledR}$ 3.0. Determinaram-se a densidade de gotas $\left(\right.$ gotas $\mathrm{cm}^{-2}$ ) e a porcentagem de cobertura, de quatro etiquetas posicionadas nos pontos cardeais e em quatro seções da planta, ou seja, região apical, mediana superior, mediana inferior e basal.

A aplicação da doses procedeu-se das $9 \mathrm{~h}$ às $10 \mathrm{~h}$ da manhã. Nesse momento, aferiu-se a temperatura $\left(25,3{ }^{\circ} \mathrm{C} \pm 1\right)$, a umidade relativa $(80 \% \pm 3)$ e a velocidade do vento $\left(2 \mathrm{~km} \mathrm{~h}^{-1}\right)$, sendo as plantas mantidas fora da casa de vegetação por 24 horas, após a aplicação do glyphosate, visando assim evitar a lavagem do produto pela água de irrigação ou da chuva.

Os parâmetros avaliados foram altura $(\mathrm{cm})$, medindo o comprimento do solo até o meristema apical das plantas; área foliar $\left(\mathrm{cm}^{2}\right)$, de acordo com o método não destrutivo proposto por Antunes et al. (2008); diâmetro do caule $(\mathrm{cm})$, medindo-se com auxílio de paquímetro o diâmetro no coleto das plantas; e número de folhas e de ramos plagiotrópicos, aos 0,45 e 120 dias após aplicação (DAA). Os sintomas de intoxicação também foram avaliados aos 10, 45 e 120 DAA, empregando-se a escala de 0 a $100 \%$, em que 0 corresponde à ausência de sintomas visíveis e $100 \%$ à morte das plantas. Aos 120 DAA, as plantas foram seccionadas rente ao solo, sendo separadas em folhas, caule e raízes, acondicionadas em sacos de papel e mantidas em estufa de circulação forçada de ar a $65^{\circ} \mathrm{C}$ até atingir peso constante, para determinação da massa seca.

Para as variáveis altura, área foliar, diâmetro do caule, número de folhas e ramos plagiotrópicos, matéria seca do caule, raízes e folhas, atribuiu-se valor de $100 \%$ para as plantas testemunhas dos dois cultivares, ou seja, plantas que não receberam tratamento com glyphosate. A partir desse valor referencial, foram calculadas, para as demais doses 
de glyphosate, porcentagens superiores ou inferiores a $100 \%$ (valor de referência), relativo ao crescimento compreendido entre 45 e 120 dias após a aplicação do herbicida. Esse procedimento foi adotado pelo fato de serem cultivares de crescimento distinto, sendo Acaiá de porte alto, com internódios longos e bom vigor vegetativo; e Catucaí, de porte baixo, com internódios curtos e bom vigor vegetativo).

Para interpretação dos dados, empregouse a análise de variância, utilizando-se o teste $\mathrm{F}(\mathrm{p} \leq 0,05)$. Verificada a significância estatística da interação, realizou-se o seu desdobramento, empregando o teste $\mathrm{F}$ a $5 \%$ de probabilidade para as comparações entre cultivares e análise de regressão para doses de glyphosate. A escolha dos modelos foi baseada na sua significância, no fenômeno biológico e no coeficiente de determinação $\left(R^{2}=\right.$ S.Q. Reg./S.Q. Trat.).

\section{RESULTADOS E DISCUSSÃO}

Para as variáveis estudadas, observaramse interações significativas entre os fatores testados (cultivares $\mathrm{x}$ doses), com exceção de diâmetro do caule, número de folhas e ramos plagiotrópicos, que, independentemente do cultivar, não foram afetados pelo herbicida.

Observou-se variação na densidade de gotas (gotas $\mathrm{cm}^{-2}$ ) e na porcentagem de cobertura entre os cultivares de café (Figura 1). A melhor distribuição das gotas ao longo do dossel das plantas ocorreu no cultivar Acaiá. Nesse cultivar a densidade de gotas e a porcentagem de cobertura para as seções das plantas 2 (mediana superior), 3 (mediana inferior) e 4 (basal) foram de 189, 171 e 169 gotas $\mathrm{cm}^{-2}$ e 27,09, 22,04 e 21,16\%, respectivamente. Já o cultivar Catucaí apresentou, nas mesmas seções, 207, 118 e 97 gotas $\mathrm{cm}^{-2}$ e 28,19, 14,65 e $10,65 \%$, respectivamente. A melhor distribuição das gotas ao longo das seções das plantas, verificada no cultivar Acaiá, deve-se, possivelmente, ao maior comprimento dos internódios. Devido à maior distância entre as folhas, foi facilitado o contato das gotas aspergidas com as etiquetas de papel fixadas. De modo inverso, no cultivar Catucaí, houve grande deposição de gotas nas folhas contidas na seção mediana superior (Figura 1), em comparação com as folhas das outras partes

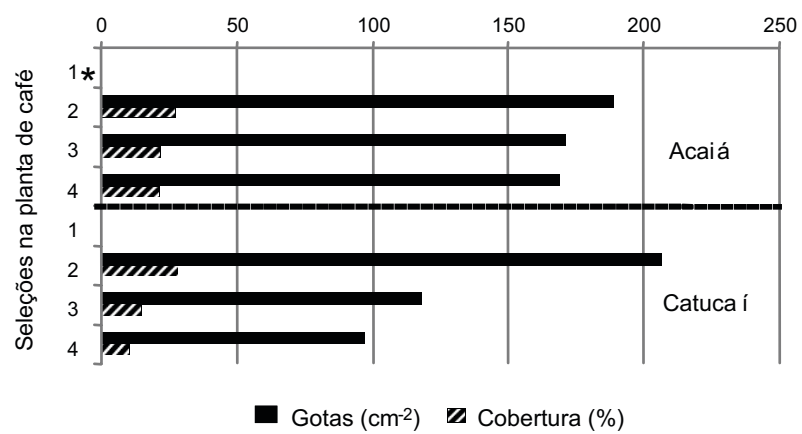

Figura 1 - Médias da densidade de gotas (gotas $\mathrm{cm}^{-2}$ ) e porcentagem de cobertura de pontas jato plano (TT11002), aplicadas em etiquetas de papel-cartão e fixadas nas folhas de dois cultivares de café, dispostas em quatro seções da planta. (*1 - apical; 2 - mediana superior; 3 - mediana inferior; 4- basal).

da planta. Isso pode ter ocorrido devido à pequena distância entre as folhas, ficando elas sobrepostas e diminuindo a superfície de contato com as gotas aspergidas. Além do mais, a área foliar média quantificada no dia da aplicação do herbicida foi de 1.009,4 e $1017,61 \mathrm{~cm}^{2}$, para Acaiá e Catucaí, respectivamente, não havendo diferença estatística.

A tolerância diferencial de plantas ao glyphosate pode ser decorrente de diferenças na interceptação, absorção e translocação até o sítio de ação com a inibição da enzima-alvo, a 5-enolpiruvil-chiquimato-3-fosfato sintase (EPSPs), além da dose do produto. Isso promove maior tolerância nas espécies que possuem mecanismos que dificultem o contato e absorção das gotas pelas folhas, como tricomas, estruturas anatômicas das superfícies foliares (camada espessa de cera e densidade estomática) e sobreposição de folhas (Reddy et al., 2008). Tuffi Santos et al. (2006) observaram que a espécie Eucalyptus resinifera foi mais tolerante ao glyphosate que E. grandis, E. pellita, E. urophylla e E. saligna. E. resinifera foi também a espécie que apresentou menor densidade de células epidérmicas. Essas células são regiões mais propensas à penetração do glyphosate, e sua densidade apresentou correlação positiva e significativa com a porcentagem de intoxicação pelo herbicida. França et al. (2010a), trabalhando com três cultivares de cafeeiro, constataram diferença entre cultivares quanto à sensibilidade ao 
glyphosate, podendo ter explicação pela base genética dos cultivares, pois os cultivares mais tolerantes se originaram de cruzamentos interespecíficos (Coffea arabica e Coffea canephora).

As plantas tratadas com glyphosate, independentemente do cultivar, apresentaram sintomas de clorose e estreitamento do limbo foliar, principalmente, nas regiões meristemáticas, a partir do sétimo dia após a aplicação (DAA), sendo esses sintomas mais pronunciados nas doses superiores a 230,4 $\mathrm{g} \mathrm{ha}^{-1}$. A clorose foliar pode ser creditada à menor sintese de clorofila, pois o glyphosate impede de modo indireto sua formação (Tan et al., 2006), o que pode resultar em menores teores de nitrogênio foliar, como constatado por França et al. (2010b). O cultivar Acaiá apresentou sintomas mais severos de intoxicação, como necrose após clorose foliar, a partir de 10 DAA, nas folhas mais novas da parte mediana da planta. Esses sintomas também foram encontrados em outros trabalhos com eucalipto e varjão (Parkia multijuga) submetidos à deriva de glyphosate (Yamashita et al., 2006; Tuffi Santos et al., 2009). Contudo, diferenças, quanto à severidade dos sintomas visuais, entre cultivares de café do mesmo porte não foram encontradas por França et al. (2010a). No entanto, Gravena et al. (2009) não observaram efeitos visuais de intoxicação em Citrus limonia com doses de até $720 \mathrm{~g} \mathrm{ha}^{-1}$ de glyphosate. Alguns herbicidas podem não apresentar sintomas de intoxicação, mas podem comprometer o crescimento e o desenvolvimento das plantas pelo resto do ciclo da cultura.

Observa-se na Figura 2 que o aumento da dose de glyphosate promoveu aumento da intoxicação das plantas de café, aos 10 DAA. Os dois cultivares testados seguiram uma tendência quadrática de aumento da intoxicação com o aumento das doses de glyphosate. Isso indicou que nas doses de 394 e 404,15 $\mathrm{g}^{\text {ha }}{ }^{-1}$ do herbicida, para Acaiá e Catucaí, respectivamente, foi observada maior porcentagem de intoxicação, havendo estabilização na intoxicação nas doses superiores.

O aumento da dose de glyphosate promoveu maior intoxicação das plantas tratadas nos dois cultivares, com percentuais de $48,68 \%$ e $31,06 \%$ para Acaiá e Catucaí, respectivamente, na dose de 460,8 $\mathrm{g}$ ha ${ }^{1}$, aos 45 DAA
(Figura 3). O cultivar Acaiá, a partir da dose de $115,2 \mathrm{~g} \mathrm{ha}^{-1}$ de glyphosate, diferenciou-se do Catucaí quanto à intoxicação promovida pelo herbicida.

De modo geral, aos 120 DAA, houve redução da intoxicação promovida pelo herbicida sobre as plantas de café, para os dois cultivares, em comparação com as avaliações realizadas aos 10 e 45 DAA (Figura 4). Doses menores que $115,2 \mathrm{~g} \mathrm{ha}^{-1}$ proporcionaram injúrias quase imperceptiveis nas plantas, sobretudo para Catucaí. Corroborando esses valores, França et al. (2010a) observaram

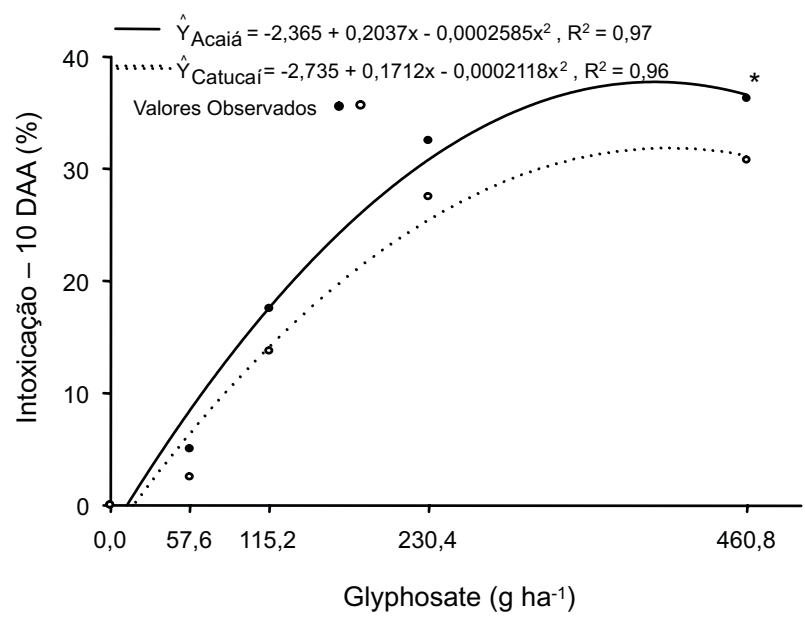

Figura 2 - Porcentagem de intoxicação de plantas de café submetidas a doses de glyphosate, aos 10 dias após a aplicação (DAA).

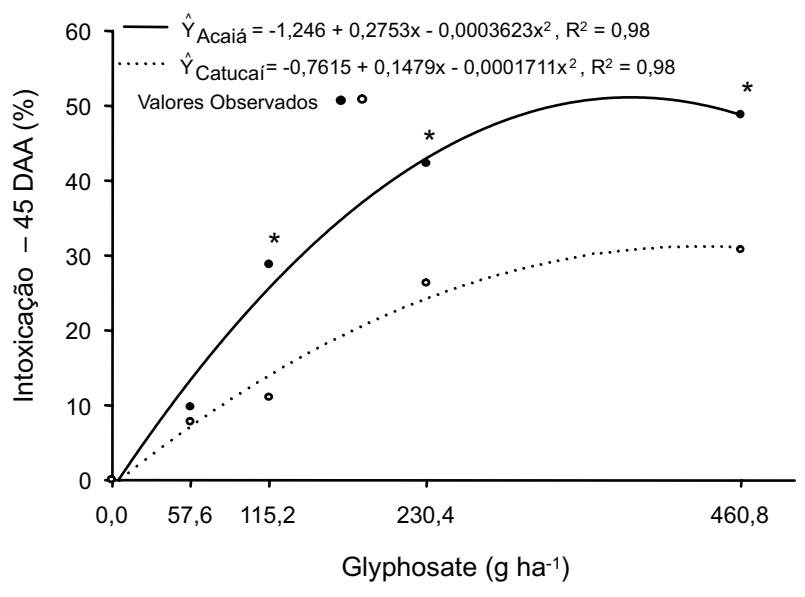

Figura 3 - Porcentagem de intoxicação de plantas de café submetidas a doses crescentes de glyphosate, aos 45 dias após a aplicação (DAA). 
recuperação das plantas aos 120 DAA, com queda do nível de intoxicação das plantas tratadas com glyphosate. Tuffi Santos et al. (2007) observaram recuperação de plantas de eucalipto tratadas com doses menores que $172,8 \mathrm{~g}^{\text {ha }}{ }^{-1}$ de glyphosate, aos 45 DAA. A recuperação de plantas tratadas com glyphosate, principalmente em doses baixas, deve-se possivelmente à metabolização do herbicida através de enzimas, como a glutamina-stransferase. Essa enzima é capaz de conjugar a molécula do glyphosate com glutamina, diminuindo o poder de toxidez nas plantas. Essas plantas foram tratadas com doses menores que $70 \mathrm{~g} \mathrm{ha}^{-1}$ de glyphosate, promovendo inicialmente injúrias nas folhas, mas retornando posteriormente ao crescimento normal da espécie.

O aumento das doses de glyphosate promoveu redução no incremento da altura das plantas para Acaiá e Catucaí (Figura 5), observando-se diferenças entre os cultivares quando submetidos à dose de 460,8 $\mathrm{g} \mathrm{ha}^{-1}$. Houve redução no incremento em altura de Acaiá em $32,37 \%$ e de Catucaí em 17,38\%, quando comparados com plantas que não receberam o tratamento com glyphosate (100\%). Do mesmo modo, França et al. (2010a) constataram menor incremento na altura das plantas de café com o aumento das doses de glyphosate, porém não apresentando diferença entre cultivares que eram de mesmo porte. Tuffi Santos et al. (2007) relataram que houve

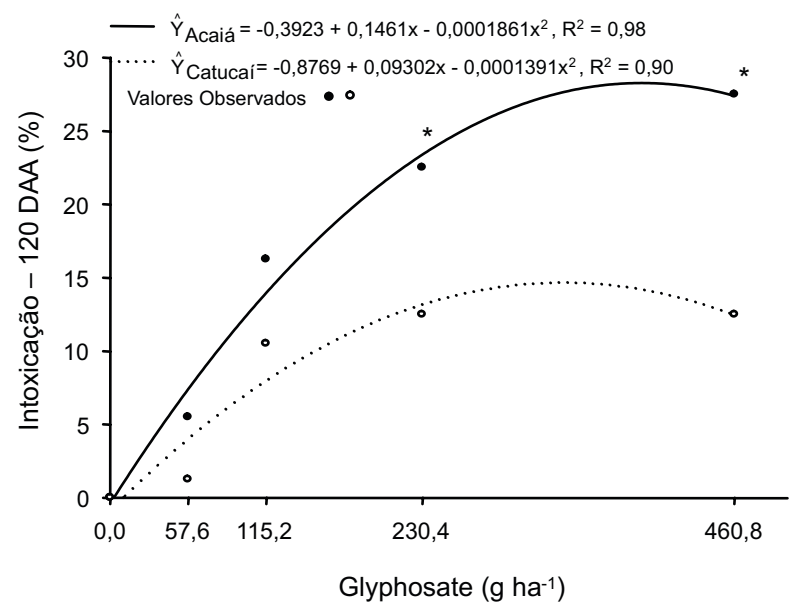

Figura 4 - Porcentagem de intoxicação de plantas de café submetidas a doses crescentes de glyphosate, aos 120 dias após a aplicação (DAA). menor crescimento de clones de eucalipto a partir da dose de $172,8 \mathrm{~g} \mathrm{ha}^{-1}$, havendo diferenças entre os clones. Doses superiores a $360 \mathrm{~g} \mathrm{ha}^{-1}$ retardaram o crescimento das plantas de varjão (Parkia multijuga) (Yamashita et al., 2006).

$\mathrm{O}$ incremento da área foliar das plantas foi comprometido com aumento das doses de glyphosate aos 45 DAA. O efeito foi maior em Acaiá, observando-se que nas doses de 230,4 e $460,8 \mathrm{~g} \mathrm{ha}^{-1}$ houve redução dessa variável de 18,61 e $28,96 \%$, respectivamente. Todavia, para Catucaí houve redução de 6,9 e $11,99 \%$, nas doses de 230,4 e 460,8 $\mathrm{g} \mathrm{ha}^{-1}$, respectivamente (Figura 6). Essa menor

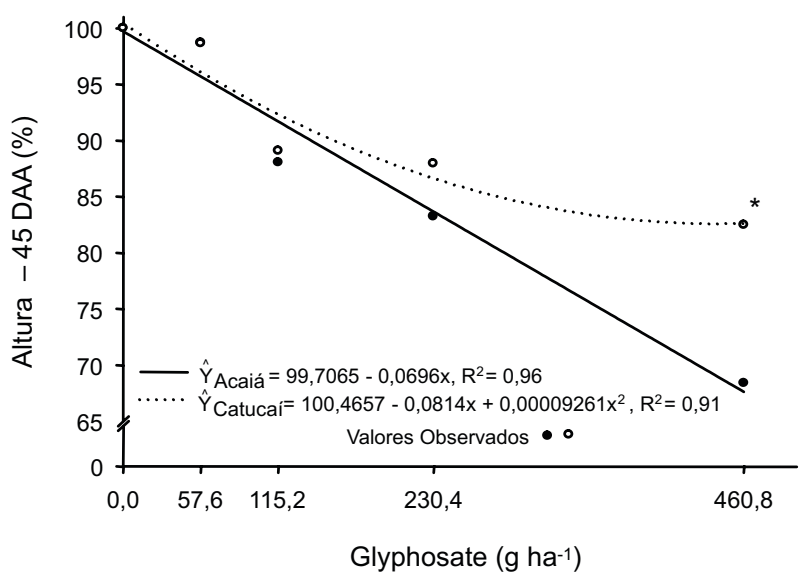

Figura 5 - Porcentagem de altura acumulada de plantas de café submetidas a doses crescentes de glyphosate em deriva simulada, aos 45 dias após a aplicação (DAA).

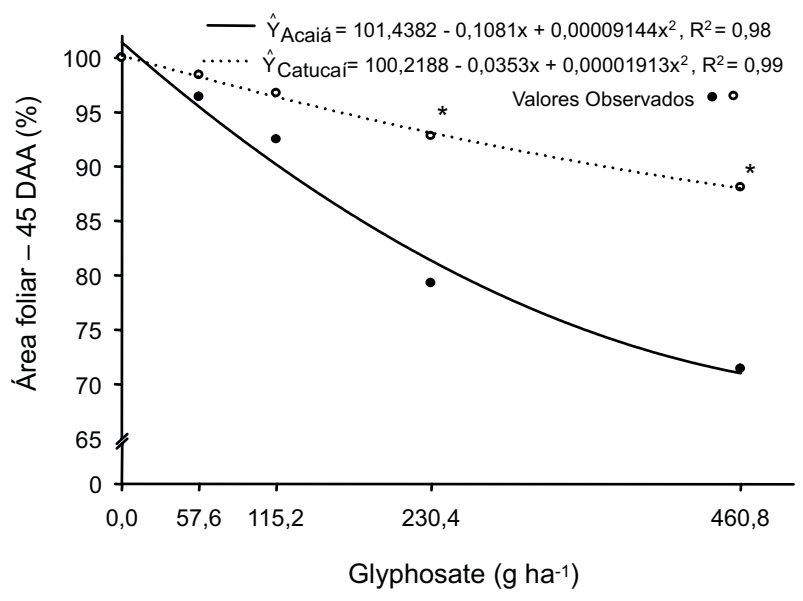

Figura 6 - Porcentagem de área foliar acumulada de plantas de café submetidas a doses crescentes de glyphosate em deriva simulada, aos 45 dias após a aplicação (DAA). 
tolerância ao glyphosate das plantas do cultivar Acaiá, em comparação com as do Catucaí, possivelmente se dá devido à maior interceptação do herbicida pelo cultivar de porte alto. Plantas do cultivar Acaiá apresentam internódios mais longos, o que favorece a passagem do glyphosate por entre suas folhas.

O aumento das doses de glyphosate promoveu redução do incremento em altura dos dois cultivares analisados, aos 120 DAA (Figura 7). Diferenças entre os cultivares foram observadas nas doses de 230,4 e 460,8 $\mathrm{g} \mathrm{ha}^{-1}$. Nessas doses, obtiveram-se reduções de 4,29 e $16,57 \%$ para Catucaí e de 16,47 e $26,86 \%$ para Acaiá, respectivamente.

A área foliar das plantas do cultivar Acaiá, nas doses de 115,2, 230,4 e 460,8 $\mathrm{g} \mathrm{ha}^{-1}$, foram reduzidas em 8,51, 16,35 e 32,02\%, respectivamente. Esse mesmo cultivar apresentou a menor área foliar, aos 120 DAA, diferenciando-se do cultivar Catucaí, para doses superiores a 115,2 $\mathrm{g} \mathrm{ha}^{-1}$ (Figura 8).

A tolerância diferencial de plantas ao glyphosate possivelmente se deve a diferenças na capacidade da espécie em desintoxicar-se, metabolizando ou degradando o produto em compostos menos tóxicos ou não tóxicos (Reddy et al., 2008). Maior sensibilidade aos efeitos do glyphosate foi observada com o cultivar Topázio, em comparação com os cultivares Catucaí e Oeiras, que possuem base genética interespecífica (Coffea arabica e Coffea canephora) (França et al., 2010a). A leguminosa Cassia occidentalis mostrou-se mais tolerante ao glyphosate, quando comparada à leguminosa Sesbania herbacea. Isso se deve ao fato de $C$. occidentalis promover maior degradação da molécula do glyphosate para metabólitos menos tóxicos, como o ácido aminometilfosfônico (AMPA) (Reddy et al., 2008).

O aumento da dose de glyphosate promoveu menor acúmulo de matéria seca nas raízes das plantas tratadas com glyphosate, aos 120 DAA (Figura 9). Nos cultivares Acaiá e Catucaí houve percentual de redução de 49,98 e $41,67 \%$, respectivamente, na dose de 460,8 $\mathrm{g} \mathrm{ha}^{-1}$. Seguindo a mesma tendência das outras variáveis analisadas, o cultivar Acaiá mostrou-se menos tolerante à intoxicação por glyphosate (doses superiores a 115,2 $\mathrm{g} \mathrm{ha}^{-1}$ ), quando comparado ao Catucaí. Do mesmo modo, Velini et al. (2008) observaram menor acúmulo de matéria seca nas raízes de plantas de Pinus e eucalipto tratadas com glyphosate. Além disso, os efeitos são mais lentos quando comparados aos verificados na parte aérea, principalmente em menores doses.

A matéria seca das folhas de plantas de Acaiá foi significativamente menor quando comparada à de Catucaí, nas doses de 115,2 e $230,4 \mathrm{~g} \mathrm{ha}^{-1}$ de glyphosate (Figura 11). No entanto, na dose de $460,8 \mathrm{~g} \mathrm{ha}^{-1}$ os cultivares

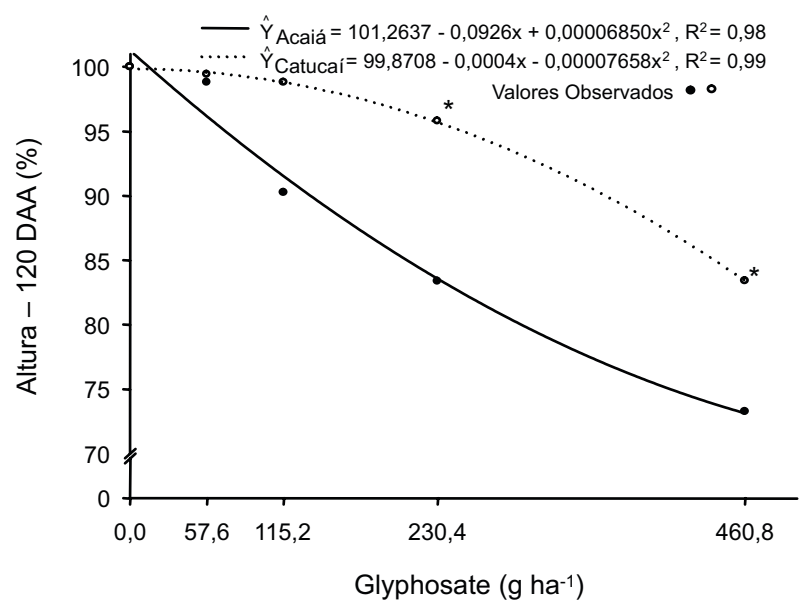

Figura 7 - Porcentagem de altura acumulada de plantas de café submetidas a doses crescentes de glyphosate em deriva simulada, aos 120 dias após a aplicação (DAA).

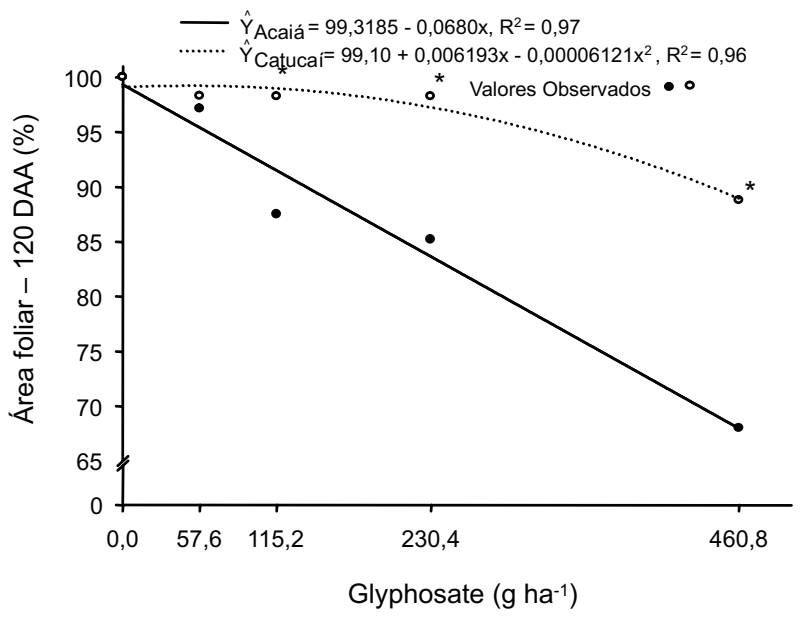

Figura 8 - Porcentagem de área foliar acumulada de plantas de café submetidas a doses crescentes de glyphosate em deriva simulada, aos 120 dias após a aplicação (DAA). 


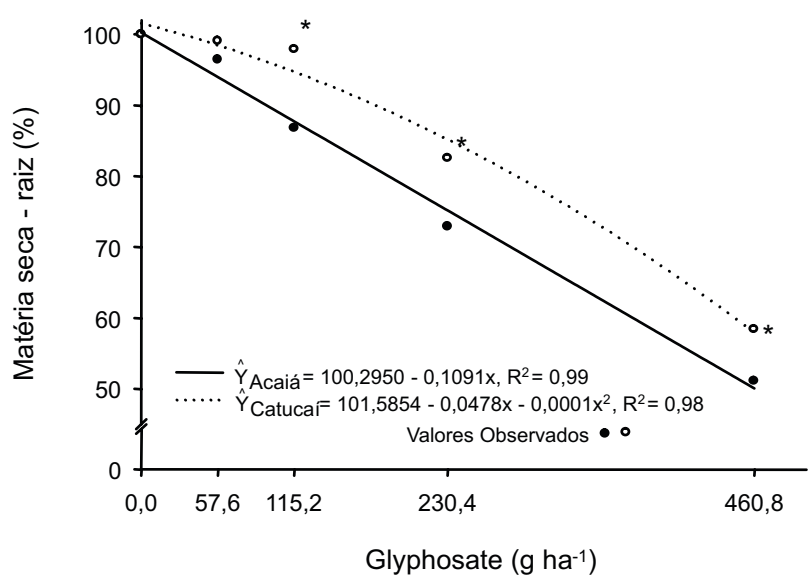

Figura 9 - Porcentagem de matéria seca acumulada nas raízes de plantas de café submetidas a doses crescentes de glyphosate em deriva simulada.

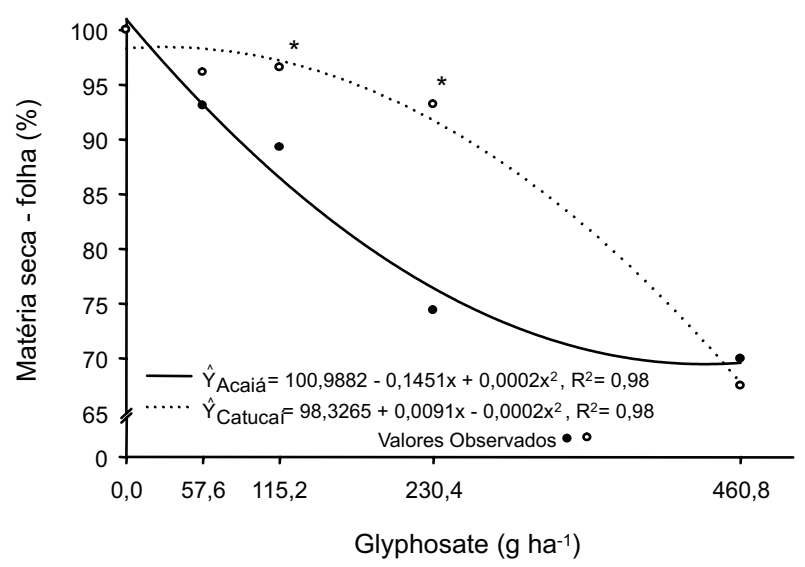

Figura 10 - Porcentagem de matéria seca acumulada no caule de plantas de café submetidas a doses crescentes de glyphosate em deriva simulada.

apresentaram similaridade quanto ao acúmulo de matéria seca pelas folhas, indicando possivelmente alta intoxicação das plantas, independentemente do cultivar.

A matéria seca do caule das plantas de Catucaí foi pouco afetada pelo aumento das doses de glyphosate, com percentuais de redução de $2,19,4,62$ e $11,76 \%$, nas doses de $115,2,230,4$ e 460,8 $\mathrm{g} \mathrm{ha}^{-1}$, respectivamente (Figura 10). Contudo, o acúmulo de matéria seca no caule por plantas do cultivar Acaiá foi comprometido, com percentual mínimo de matéria seca de $73,86 \%$, na dose de $306,17 \mathrm{~g} \mathrm{ha}^{-1}$ de glyphosate. Relação direta

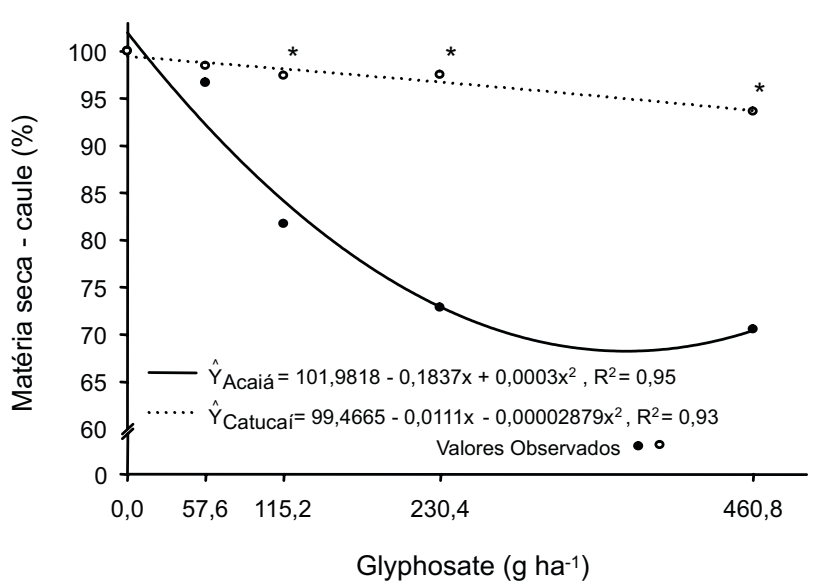

Figura 11 - Porcentagem de matéria seca acumulada nas folhas de plantas de café submetidas a doses crescentes de glyphosate em deriva simulada.

entre o aumento da dose de glyphosate e a redução no acúmulo de massa de matéria seca pelas plantas também foi observada por França et al. (2010a) aos 120 DAA, independentemente do cultivar utilizado.

Conclui-se que os sintomas de intoxicação causados pelo glyphosate nas plantas de café dos cultivares Acaiá e Catucaí foram clorose e estreitamento do limbo foliar e necrose nas folhas de Acaiá. Este cultivar é menos tolerante ao glyphosate, quando comparado ao Catucaí, isto é, suas plantas apresentam menor crescimento quando submetidas ao tratamento com o glyphosate.

\section{AGRADECIMENTOS}

Ao Conselho Nacional de Desenvolvimento Científico e Tecnológico - CNPq, pela concessão da bolsa de estudos, e à Fundação de Amparo à Pesquisa do Estado de Minas Gerais - FAPEMIG, pela concessão dos recursos para a realização deste trabalho.

\section{LITERATURA CITADA}

COMPANHIA NACIONAL DE ABASTECIMENTO CONAB. Acompanhamento da safra brasileira café. Safra 2012, segunda estimativa, Maio/2012. Disponível em: <http:// www.conab.gov.br>. Acesso em: 4 jun. 2012

ANTUNES, W. C. et al. Allometric models for non-destructive leaf area estimation in coffee (Coffea arabica and Coffea canephora). Ann. Appl. Biol., v. 153, n. 1, p. 33-40, 2008. 
FRANÇA, A. C. et al. Crescimento de cultivares de café arábica submetidos a doses do glyphosate. Planta Daninha, v. 28, n. 3, p. 599-607, 2010a.

FRANÇA, A. C. et al. Teores de nutrientes em cultivares de café arábica submetidos à deriva de glyphosate.

Planta Daninha, v. 28, n. 4, p.877-885, 2010b.

GRAVENA, R. et al. Low glyphosate rates do not affect Citrus limonia (L.) Osbeck seedlings. Pest. Manag. Sci., v. 65 , n. 4, p. 420-425, 2009

GUIMARÃES, P. T. G. et at. Cafeeiro. In: COMISSÃO DE FERTILIDADE DO SOLO DO ESTADO DE MINAS

GERAIS. Recomendações para uso de corretivos e fertilizantes em Minas Gerais: $5^{\text {a }}$ aproximação. Viçosa, MG, 1999. p. 289-302.

REDDY, K. N. et al. Aminomethylphosphonic acid accumulation in plant species treated with glyphosate. J. Agric. Food Chem., v. 56, n. 6, p. 2125-2130, 2008.

RONCHI, C. P. et al. Acúmulo de nutrientes pelo cafeeiro sob interferência de plantas daninhas. Planta Daninha, v. 21, n. 2, p. 219-227, 2003.

SILVA, A. A.; RONCHI, C. P. Manejo e controle de plantas daninhas em café. In: VARGAS, L; ROMAN, E. S. (Org.).

Manual de manejo e controle de plantas daninhas. Passo Fundo: Embrapa Trigo, 2008. p. 417-475.
TAN, S. et al. Herbicidal inhibitors of amino acid biosynthesis and herbicide-tolerant crops. Amino Acids, v. 30, n. 2, p. 195-204, 2006.

TUFFI SANTOS, L. D. et al. Intoxicação de espécies de eucalipto submetidas à deriva do glyphosate.

Planta Daninha, v. 24, n. 2, p. 359-364, 2006.

TUFFI SANTOS, L. D. et al. Morphological responses of different eucalypt clones submitted to glyphosate drift.

Environ. Exper. Bot., v. 59, n. 1, p. 11-20, 2007.

TUFFI SANTOS, L. D. et al. Leaf anatomy and morphometry in three eucalypt clones treated with glyphosate. Braz. J. Biol., v. 69, n. 1, p. 129-136, 2009.

VELINI, E. D. et al. Glyphosate applied at low doses can stimulate plant growth. Pest. Manag. Sci., v. 64, n. 4, p. 489-496, 2008.

WOLF, T. M. et al. Effect of protective shields on drift and deposition characteristics of Field sprayers. The role of application factors in the effectiveness and drift of herbicides. Regina, SK, Canada: Agriculture Canada Research Station, 1992. p. 29-52.

YAMASHITA, O. M. et al. Resposta de varjão (Parkia multijuga) a subdoses de glyphosate. Planta Daninha, v. 24, n. 3, p. 527-531, 2006. 